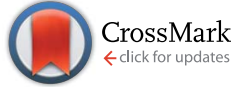

Cite this: RSC Adv., 2017, 7, 2435

Received 4th November 2016 Accepted 28th November 2016

DOI: $10.1039 / c 6 r a 26284 h$

www.rsc.org/advances

\section{Polyethylene glycol 400 (PEG400) affects the systemic exposure of oral drugs based on multiple mechanisms: taking berberine as an example}

\begin{abstract}
Bing-Liang Ma,,$^{a}$ Yan Yang, $\dagger^{a}$ Yan Dai, ${ }^{a}$ Qiao Li, ${ }^{a}$ Ge Lin*b and Yue-Ming Ma ${ }^{\star a}$
Polyethylene glycol 400 (PEG400) is a commonly used co-solvent. Recent studies suggested that it might affect the systemic exposure of oral drugs based on mechanisms besides increasing their solubility. In this study, we systematically explored the dose related effects and underlying mechanisms of PEG400 on the systemic exposure of oral berberine, a new drug candidate having multiple pharmacological effects. The results showed that low concentration (5\% and 15\%) PEG400 decreased but high concentration (50\%) PEG400 increased the absorption of berberine across mouse gut sacs by 6.5 -fold. As expected, $50 \%$ PEG400 increased the solubility of berberine from 1.7 to $10.5 \mathrm{mg} \mathrm{mL}^{-1}$. Surprisingly, $50 \%$ PEG400 reversibly opened intestinal paracellular tight junctions, which was verified by the increased absorption of the marker compound, fluorescein isothiocyanate-labeled dextran (molecular weight $\left[M_{\mathrm{w}}\right]: 4400 \mathrm{~g}$ $\left.\mathrm{mol}^{-1}, \mathrm{FD} 4\right)$. However, 50\% PEG400 did not influence the intestinal efflux, liver uptake, or hepatic metabolism of berberine. The systemic exposure $\left(\mathrm{AUC}_{0-4} \mathrm{~h}\right)$ of berberine in mice receiving orally administered berberine (200 mg kg-1) dissolved in water or $50 \%$ PEG400 reached $30.6 \mathrm{ng} \mathrm{h} \mathrm{mL}^{-1} \mathrm{or}^{-}$ $188.1 \mathrm{ng} \mathrm{h} \mathrm{mL} \mathrm{m}^{-1}$, respectively. The enhancive effect of PEG400 was significantly inhibited by cycloheximide pretreatment. In conclusion, our data showed that high concentration of PEG400 increased the systemic exposure of berberine by increasing its solubility, prompting its intestinal paracellular absorption and lymphatic transport. Our results provide new insights into the effects and mechanisms of PEG400 on the systemic exposure of oral drugs. In addition, the results would encourage further exploration on the application of PEG400 in drug delivery.
\end{abstract}

\section{Introduction}

Solubility is one of the fundamental parameters controlling oral drug absorption. ${ }^{1}$ Poor aqueous solubility usually leads to limited systemic exposure of oral drugs. Various solubilityenhancing approaches have been developed and are routinely used to tackle this problem. ${ }^{2}$ The application of co-solvent, such as polyethylene glycol 400 (PEG400), ${ }^{2}$ is one of the commonly used techniques for improving solubility.

PEG400 is usually considered as inert. ${ }^{3}$ However, recent studies have revealed that this compound has various bioactivities. For example, PEG400 inhibits drug efflux transporters such as p-glycoprotein (P-gp) ${ }^{4}$ and uptake transporters like organic anion-transporting polypeptide (OATP) 1A2. ${ }^{5}$ PEG400

\footnotetext{
${ }^{a}$ Department of Pharmacology, School of Pharmacy, Shanghai University of Traditional Chinese Medicine, 1200 Cai Lun Road, Shanghai, 201203, China. E-mail: mayueming_117@hotmail.com; Fax: +86-21-5132-2386; Tel: +86-21-5132-2386

${ }^{b}$ School of Biomedical Sciences, Faculty of Medicine, The Chinese University of Hong Kong, Lo Kwee-Seong Integrated Biomedical Sciences Building, Room 505A, Area 39, Shatin, Hong Kong, China. E-mail: linge@cuhk.edu.hk; Fax: +86-852-2603-5123; Tel: +86-852-3943-6824

$\dagger$ The authors contributed equally.
}

also inhibits drug metabolizing enzymes, including intestinal ${ }^{6}$ and hepatic cytochrome P450 3A (CYP3A). ${ }^{7}$ In addition, PEG400 accelerates gastrointestinal transit. ${ }^{8,9}$ Other studies have shown that PEG400 affects the permeability of drugs. For example, PEG400 decreases the apparent permeability of carbamazepine by reducing its thermodynamic activity and by reversing solvent drug. ${ }^{10,11}$ In contrast, PEG400 increases the permeability of testosterone across a phospholipid vesicle-based barrier. ${ }^{\mathbf{1 2}}$ Bendels et $a .^{\mathbf{1 3}}$ reported that PEG400 causes enhanced permeability of weak acids and neutral compounds but depressed permeability of weak bases. Thus, the diverse effects of PEG400 on solubility, permeability, drug metabolizing enzymes, transporters, and gastrointestinal transit time may have profound influences on the intestinal absorption and systemic exposure of oral drugs. However, although PEG400 is widely used, systematic studies on the influences of PEG400 on the systemic exposure of oral drugs and underlying mechanisms have not been reported.

Berberine (Fig. 1), an isoquinoline alkaloid isolated from medicinal plants including plants of the family Ranunculaceae, such as Coptis chinensis Franch, ${ }^{\mathbf{1 4}}$ has been reported to have multiple pharmacological effects, ${ }^{15}$ including antidiabetic, ${ }^{16}$ lipidreducing, ${ }^{17}$ anticancer ${ }^{18}$ anti-inflammatory, ${ }^{19}$ antidiarrheal, ${ }^{20}$ and 
<smiles>COc1ccc2cc3[n+](cc2c1OC)CCc1cc2c(cc1-3)OCO2</smiles>

Fig. 1 Structure of berberine.

antimicrobial $^{21}$ activities. Berberine was introduced in clinical practice in Europe in 2014 because of its beneficial effects on treating type 2 diabetes mellitus and improving lipid metabolism in patients. ${ }^{22}$ However, due to its poor aqueous solubility, ${ }^{23}$ extensive first pass metabolism, ${ }^{24}$ and efflux by intestinal ${ }^{25}$ and hepatic P-gp, ${ }^{26}$ the systemic exposure of berberine is extremely low $(0.36 \%){ }^{24}$ this dramatically limits its clinical applications. Thereby, a lot of strategies have been developed to promote the intestinal absorption of oral berberine. ${ }^{27}$ PEG400 has been used with other excipients to increase the systemic exposure of oral berberine. ${ }^{28,29}$ However, the effects of PEG400 alone and underlying mechanisms have not been systematically evaluated.

In this study, we aimed to systematically evaluate the concentration related effects and underlying mechanisms of PEG400 on the intestinal absorption and systemic exposure of oral drugs taking berberine as an example. Although the result of this study would not directly encourage the clinical applications of high concentration of PEG400, it does provide new insights into the pharmaceutical effects of PEG400.

\section{Materials and methods}

\section{Materials}

Berberine hydrochloride and palmatine hydrochloride with purities of more than $98 \%$ were obtained from the National Institute for the Control of Pharmaceutical and Biological Products (Beijing, China). Berberrubine and demethyleneberberine with purities of more than $98 \%$ were synthesized and identified as reported. ${ }^{30}$ Polyethylene glycol 400 (PEG400), fluorescein isothiocyanate-labeled dextran (molecular weight $\left.\left[M_{\mathrm{w}}\right]: 4400 \mathrm{~g} \mathrm{~mol}^{-1}, \mathrm{FD} 4\right)$, the QuantiPro bicinchoninic acid (BCA) assay kit, and reduced nicotinamide adenine dinucleotide phosphate (NADPH) were purchased from Sigma-Aldrich (St. Louis, MO, USA). The lactate dehydrogenase (LDH) activity assay kit was purchased from keyGEN BioTECH (Nanjing, China). Acetonitrile was the product of Merck (Darmstadt, Germany). Pure water used in the current study was prepared using a Milli-Q system (Millipore Corporation, Billerica, MA, USA). All other materials were of analytical grade or better.

\section{Animals}

Grade II male and female Kun-Ming (KM) mice (22-24 g) were purchased from Shanghai Slac Laboratory Animal Co., Ltd.
(Shanghai, China). The mice were housed in an air-conditioned room at $22-24{ }^{\circ} \mathrm{C}$ under a $12 \mathrm{~h}$ dark/light cycle and given food and water ad libitum. The mice were fasted overnight before the experiments. All animal experimental protocols were approved by the Institutional Animal Care and Use Committee of Shanghai University of Traditional Chinese Medicine (Approval Number: 2015007), and all experiments were performed according to the guideline of this committee.

\section{Validated high-performance liquid chromatography (HPLC) with ultraviolet (UV) detection ${ }^{30}$}

The HPLC was equipped with a 2695 separation module, a 2487 dual-wavelength absorbance detector, and an Empower2 Chemstation (Waters, Milford, MA, USA). Separation and determination were performed using an XTerra RP 18 analytical column $(5 \mu \mathrm{m}, 3.9 \times 150 \mathrm{~mm}$; Waters $)$ at $35^{\circ} \mathrm{C}$, with detection at $346 \mathrm{~nm}$. The samples were eluted through the column with a gradient of water/formic acid/triethylamine (100: $0.1: 0.2, \mathrm{v} /$ $\mathrm{v} / \mathrm{v}$ ) and methanol ( $0 \mathrm{~min}, 75: 25 ; 15 \mathrm{~min}, 60: 40 ; 15.5 \mathrm{~min}$, $75: 25 ; 20 \mathrm{~min}, 75: 25)$ at a flow rate of $0.5 \mathrm{~mL} \mathrm{~min}^{-1}$. The standard sets had good linearity within their own quantitative range [0.078-2.5 $\mu \mathrm{M}$ for berberrubine and demethyleneberberine, two major phase I metabolites of berberine ${ }^{30}$. The accuracy, precision, recovery, and stability tests all met the requirements of the quantitative determination in biological samples.

\section{Validated liquid chromatography tandem mass spectrometry (LC-MS/MS) $^{30}$}

Briefly, a Shimadzu Prominence UFLCXR series HPLC (Shimadzu, Japan) and a Thermo Scientific TSQ Quantum Ultra mass spectrometer (Thermo Scientific, Waltham, MA, USA) equipped with an electrospray ionization (ESI) source were used. To avoid the ion suppression caused by PEG400, ${ }^{31}$ palmatine, a homologous compound of berberine, was used as internal standard. The samples were precipitated with three volumes of acetonitrile. After centrifugation $(24000 \times g, 6 \mathrm{~min}$, $4{ }^{\circ} \mathrm{C}$ ), the supernatant was mixed with an equal volume of water, and $10 \mu \mathrm{L}$ samples were injected into the LC-MS/MS system. The samples were eluted through a Hypersil Gold (C18) analytical column $(5 \mu \mathrm{m}, 100 \times 2.1 \mathrm{~mm})$ with a gradient of the aqueous phase $(0.08 \% \mathrm{v} / \mathrm{v}$ formic acid and $2 \mathrm{mM}$ ammonium acetate) and the acetonitrile phase (0 $\mathrm{min}, 85: 15 ; 7 \mathrm{~min}, 32: 68$; $7.01 \mathrm{~min}, 85: 15 ; 10 \mathrm{~min}, 85: 15)$ at a flow rate of $0.3 \mathrm{~mL} \mathrm{~min}^{-1}$. The ESI source was set to positive ion mode. Data acquisition was performed in the multiple reaction monitoring mode of the selective mass transition for each compound. The transitions from the precursor ions to the protonated fragment product ions were monitored as follows: $\mathrm{m} / \mathrm{z} 336.2$ to $\mathrm{m} / \mathrm{z} 322.3$ for berberine; $\mathrm{m} / \mathrm{z} 352.1$ to $\mathrm{m} / \mathrm{z} 336.1$ for palmatine; $\mathrm{m} / \mathrm{z} 322.1$ to $\mathrm{m} / \mathrm{z}$ 307.2 for demethyleneberberine; and $\mathrm{m} / \mathrm{z} 324.1$ to $\mathrm{m} / \mathrm{z} 308.2$ for berberrubine. The linear dynamic ranges in the biological

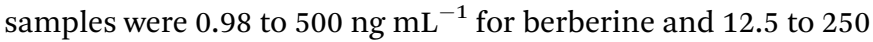
$\mathrm{ng} \mathrm{mL}^{-1}$ for berberrubine and demethyleneberberine. The accuracy, precision, recovery, and stability tests all met the requirements of the quantitative determination in biological samples. 


\section{Mouse gut sacs studies ${ }^{30}$}

Effects of PEG400 on the absorption of berberine across mouse gut sacs. Mice were divided into four groups $(n=4$ mice per group: two males and two females) in order to study the absorption of berberine $(50 \mu \mathrm{M})$ in blank Krebs-Ringer buffer (containing $118 \mathrm{mM} \mathrm{NaCl}, 25 \mathrm{mM} \mathrm{NaHCO}, 1.2 \mathrm{mM} \mathrm{MgSO}$, $2.5 \mathrm{mM} \mathrm{CaCl}_{2}, 11 \mathrm{mM}$ glucose, $1.2 \mathrm{mM} \mathrm{KH}_{2} \mathrm{PO}_{4}$, and $4.7 \mathrm{mM} \mathrm{KCl}$, $\mathrm{pH} 6.9)$ or with various concentrations $(5 \%, 15 \%$, and $50 \%)$ of PEG400. Briefly, the mice were sacrificed, and the ileum was removed $5 \mathrm{~cm}$ above the caecum after laparotomy. The ileum was washed with chilled Krebs-Ringer buffer without eversion. A $12 \mathrm{~cm}$ segment was cut and ligated at one end. The gut sac was filled on the mucosal side (inside) with $1 \mathrm{~mL}$ berberine solution and the other end was tightly ligated to create a gut sac. The sac was immediately incubated for $5 \mathrm{~min}$ at $37{ }^{\circ} \mathrm{C}$ in a Magnus bath containing $20 \mathrm{~mL}$ oxygenated Krebs-Ringer buffer. After the incubation, aliquots of buffer $(50 \mu \mathrm{L})$ were taken from the serosal side (outside) every 15 to $60 \mathrm{~min}$ and replaced with an equal volume of the Krebs-Ringer buffer. The concentration of berberine in each sample was measured using the LC-MS/MS method.

Effects of PEG400 pretreatment on the absorption of berberine across mouse gut sacs. Mice were divided into four groups ( $n=4$ mice per group: two males and two females). The mice were orally administered water or various concentrations (5\%, 15\%, and 50\%) of PEG400 aqueous solution. The intestines were collected $4 \mathrm{~h}$ later and completely washed with blank Krebs-Ringer buffer. The absorption of berberine in the absence of PEG400 across each mouse gut sac was analyzed as described above (experiment: effects of PEG400 on the absorption of berberine across mouse gut sacs, abridged as gut sac experiment 1).

Effects of PEG400 on berberine efflux across mouse gut sacs. In general, the experiment was performed as described above (gut sac experiment 1), except that the ileums were everted. Accordingly, the everted sacs were filled on the serosal side (inside) with berberine solution, and aliquots $(50 \mu \mathrm{L})$ were taken from the mucosal side (outside).

Effects of PEG400 on the absorption of FD4 across mouse gut sacs. The in vitro absorption of FD4 $\left(3 \mathrm{mg} \mathrm{mL}{ }^{-1}\right)$ in the presence of various concentrations $(5 \%, 15 \%$, and $50 \%)$ of PEG400 across each mouse gut sac was performed as described above (gut sac experiment 1). The concentrations of FD4 were determined using a fluorescence microplate reader (BioTek Instruments, Winooski, VT, USA), with excitation at $485 \mathrm{~nm}$ and emission at $528 \mathrm{~nm} .^{30}$

Effects of PEG400 pretreatment on the absorption of FD4 across mouse gut sacs. Mice were divided into three groups $(n=$ 4 mice per group: two males and two females). The mice were orally administered 50\% PEG400 aqueous solution. The intestines were collected 2 or $4 \mathrm{~h}$ later and completely washed with blank Krebs-Ringer buffer. The in vitro absorption of FD4 in the absence of PEG400 across each mouse gut sac was then analyzed as described above (gut sac experiment 1). The concentrations of FD4 were determined as described in the experiment: effects of PEG400 on the absorption of FD4 across mouse gut sacs.

\section{Solubility of berberine in PEG400 solution}

We analyzed the solubility of berberine in high-concentration PEG400 as previously described..$^{32}$ Briefly, $10 \mathrm{mg}$ berberine was added to $1 \mathrm{~mL}$ water or 50\% PEG400. The berberine concentrations were in accordance with those used in the pharmacokinetic studies. The suspensions were subjected to sonication for $1 \mathrm{~h}$ and then kept at room temperature (about 22 ${ }^{\circ} \mathrm{C}$ ) for $5 \mathrm{~h}$. The samples were centrifuged at $24000 \times g$ for $6 \mathrm{~min}$. The supernatants were collected and diluted, and the berberine concentration in each sample was measured using the LC-MS/MS method. All experiments were performed in triplicate.

\section{Effects of PEG400 on the in vitro metabolism of berberine b $^{30}$}

In brief, reaction conditions, including the protein concentration and the incubation time, were optimized to ensure the linearity of the reactions. ${ }^{30}$ The reactions were conducted in $100 \mathrm{mM}$ PBS buffer (pH 7.4) containing $1 \mathrm{mM}$ NADPH, $0.5 \mathrm{mg}$ of microsomal protein, various concentration of berberine (3.625, $6.25,12.5,25,50,100,200$, and $400 \mu \mathrm{M}$ ), and various concentration of PEG400 $(0 \%, 0.3 \%, 1 \%$, and $3 \%)$. The concentrations of PEG400 were chosen according to its in vivo exposure levels after receiving oral PEG400. ${ }^{33}$ After pre-incubation for $5 \mathrm{~min}$, the reaction was initiated with addition of the NADPH solution. Samples were then incubated at $37{ }^{\circ} \mathrm{C}$ for $15 \mathrm{~min}$, and the reactions were terminated by the addition of an equal volume of ice-cold methanol. After centrifugation (16 $000 \mathrm{rpm}, 5 \mathrm{~min}, 4$ ${ }^{\circ} \mathrm{C}$ ), the samples were analyzed using the HPLC method. All reactions were performed in triplicate.

\section{Effects of PEG400 on the in situ liver uptake of berberine ${ }^{34}$}

Briefly, under light ether anesthesia with diethyl ether, berberine $(100 \mu \mathrm{M})$ dissolved in saline or various concentrations of PEG400 $\left(0.5 \%, 1.5 \%\right.$, and $5 \%, 0.04 \mathrm{~mL} \mathrm{~kg}^{-1}$ body weight) was injected rapidly into the portal vein of mice. The concentrations of PEG400 were chosen according to its in vivo exposure levels after receiving oral PEG400. ${ }^{33}$ The liver was excised $18 \mathrm{~s}$ later and weighed. The livers were homogenized, and the concentrations of berberine were detected using the LCMS/MS method.

\section{Pharmacokinetics of berberine in mice}

Effects of high-concentration PEG400 on the pharmacokinetics of berberine. Mice were randomly divided into eight groups ( $n=8$ mice per group: four males and four females). The mice were orally administered $200 \mathrm{mg} \mathrm{kg}^{-1}$ berberine dissolved in water or $50 \%$ PEG400 at the dose volume of $0.2 \mathrm{~mL} / 10 \mathrm{~g}$ body weight. The dose of berberine $\left(200 \mathrm{mg} \mathrm{kg}^{-1}\right.$ ) was chosen according to the dose used in the clinic and in other preclinical studies using mice..$^{35,36}$ Blood was collected into heparinized tubes at the designated time points $(0.5,1,2$, and $4 \mathrm{~h})$. The last time point was selected to allow sampling prior to death induced by oral berberine in 50\% PEG400. After centrifugation $\left(24000 \times g, 6 \mathrm{~min}, 4^{\circ} \mathrm{C}\right)$, the plasma samples were collected, 
and the concentration of berberine was detected using the LCMS/MS method.

Effects of cycloheximide pretreatment on the promotive effect of high-concentration PEG400. Mice were randomly divided into eight groups $(n=6$ mice per group: three males and three females). The mice received an intraperitoneal injection of saline or cycloheximide $\left(10 \mathrm{mg} \mathrm{kg}^{-1}\right)$ to block chylomicron flow. ${ }^{37}$ Two hours later, the mice were orally administered $200 \mathrm{mg} \mathrm{kg}^{-1}$ berberine dissolved in 50\% PEG400. Plasma samples were prepared and analyzed as above (experiment: effects of high-concentration PEG400 on the pharmacokinetics of berberine).

\section{Assessment of intestinal membrane damage}

The release of protein and LDH from the intestinal epithelial cells was measured as a marker of intestinal membrane damage as reported previously. ${ }^{38}$ Mice were divided into two groups $(n=$ 4 mice per group: two males and two females). The mice were orally administered water or 50\% PEG400 aqueous solution. The intestines were collected $4 \mathrm{~h}$ later and washed with blank the Krebs-Ringer buffer. LDH activity of the perfusate was determined using an LDH activity assay kit, and protein concentrations were determined using a QuantiPro BCA assay kit with bovine serum albumin as the standard.

\section{Statistical analysis}

Results were expressed as the mean $\pm \mathrm{SD}$, and statistical significance was determined with one-way or two-way analysis of variance (ANOVA) for multiple comparisons with the minimum level of significance $(P<0.05)$.

\section{Results}

\section{Effects of PEG400 on the absorption and efflux of berberine} across mouse gut sacs

As shown in Fig. 2A, the absorption of berberine at 60 min were $3.8 \pm 3.1,1.2 \pm 0.6,2.7 \pm 1.3,25.3 \pm 8.7$, and $0.19 \pm 0.17 \mathrm{ng}$ $\mathrm{mL}^{-1} \mathrm{~cm}$ sac in control, various concentrations of PEG400 (5\%, $15 \%$, or $50 \%$ ) treated, and $50 \%$ PEG400 pretreated groups, respectively. The results showed that 5\% PEG400 decreased while 50\% PEG400 increased the absorption of berberine across mouse gut sacs (both $p<0.01$ ). However, 15\% PEG400 did not have any significant effects on berberine absorption $(p>0.05)$. Interestingly, pretreatment with 50\% PEG400 decreased the absorption of berberine $(p<0.01)$.

As shown in Fig. 2B, the efflux of berberine at $60 \mathrm{~min}$ were $30.4 \pm 2.6$ and $30.9 \pm 6.8 \mathrm{ng} \mathrm{mL}{ }^{-1} \mathrm{~cm} \mathrm{sac}$ in the control and $50 \%$ PEG400-treated groups, respectively. The results showed that $50 \%$ PEG400 did not inhibit the efflux of berberine across the gut sacs $(p>0.05)$.

\section{Effects of high-concentration PEG400 on the absorption of FD4 across mouse gut sacs}

As shown in Fig. 3A, the absorption of FD4 at 60 min were 0.38 $\pm 0.19,0.24 \pm 0.06,0.18 \pm 0.07$, and $5.0 \pm 2.0 \mathrm{ng} \mathrm{mL}^{-1} \mathrm{~cm} \mathrm{sac}$ in control, $5 \%, 15 \%$, or $50 \%$ PEG400 treated groups, respectively. The results showed that $50 \%$ PEG400 increased the absorption of FD4 across mouse gut sacs $(p<0.01)$.

As shown in Fig. 3B, the absorption of FD4 at 60 min were 0.72 $\pm 0.18,0.63 \pm 0.16$, and $0.85 \pm 0.38 \mathrm{ng} \mathrm{mL}{ }^{-1} \mathrm{~cm} \mathrm{sac}$ in control mice and mice pretreated with $50 \%$ PEG400 for 2 or $4 \mathrm{~h}$, respectively. The results showed that pretreatment with $50 \%$ PEG400 for $2 \mathrm{~h}$ decreased the absorption of FD4 (Fig. 3B, $p<0.05$ ).

\section{Effects of PEG400 on intestinal damage}

As shown in Fig. 4, the total intestinal protein levels were not increased at $4 \mathrm{~h}$ after oral administration in the presence of $50 \%$ PEG400 $(p>0.05)$. The activities of LDH in the intestinal perfusates of both the control and 50\% PEG400-treated groups were barely detectable.

\section{Effects of PEG400 on the in situ hepatic uptake of berberine}

As shown in Fig. 5, PEG400 did not influence the in situ hepatic uptake of berberine $(p>0.05)$.

\section{Effects of PEG400 on the phase I metabolism of berberine}

As shown in Fig. 6A and B, PEG400 significantly inhibited the formation of the major in vitro phase I metabolites (berberrubine and demethyleneberberine) of berberine in mouse hepatic microsomes in a concentration-dependent manner

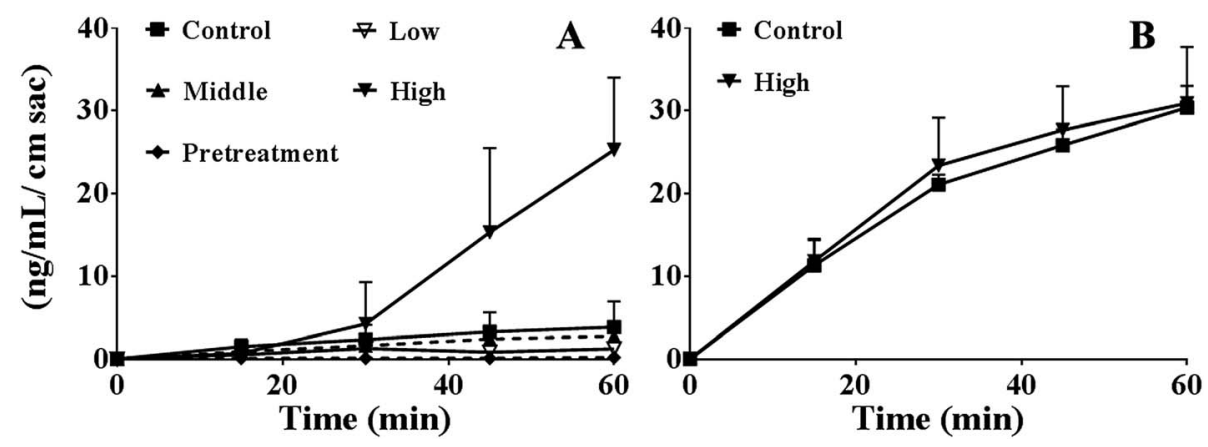

Fig. 2 Effects of PEG400 on the permeability (A) and efflux (B) of berberine (50 $\mu$ M) across mouse gut sacs (mean $\pm S D, n=3-8)$. (A) Permeability of berberine across mouse gut sacs in the presence of various concentrations (low, middle, and high: $5 \%, 15 \%$, and $50 \%$, respectively) or after pretreatment with $50 \%$ PEG400 solution. (B) Efflux of berberine $(50 \mu \mathrm{M})$ across mouse gut sacs in the presence of $50 \%$ PEG400 solution. 

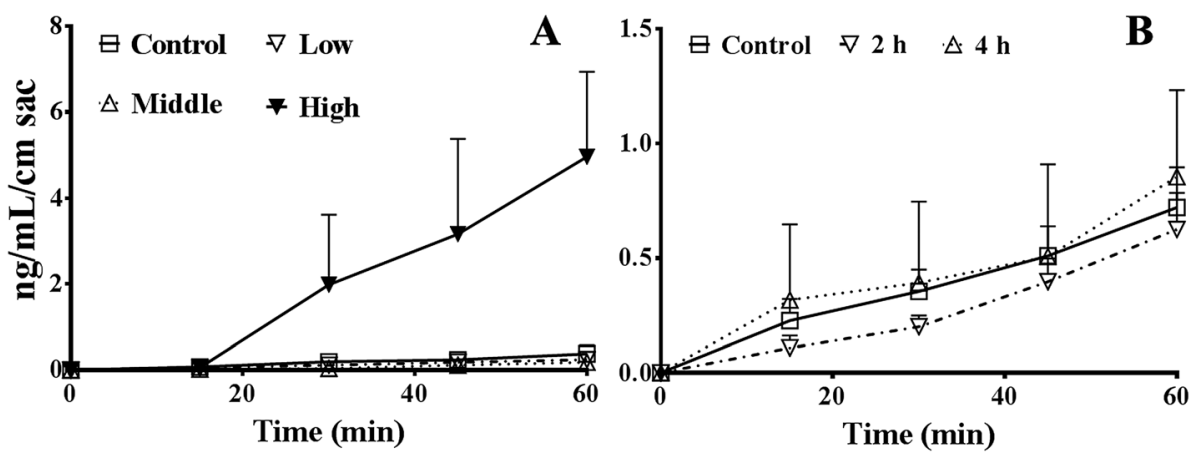

Fig. 3 Effects of PEG400 on the permeability of FD4 (3 mg mL ${ }^{-1}$ ) across mouse gut sacs (mean \pm SD, $\left.n=3-4\right)$. (A) Permeability of FD4 across mouse gut sacs in the presence of various concentrations (low, middle, and high: $5 \%, 15 \%$, and 50\%, respectively) of PEG400. (B) Permeability of FD4 across mouse gut sacs after pretreatment with 50\% PEG400 solution for 2 or $4 \mathrm{~h}$.

(both $p<0.01$ ). However, the calculated metabolizing indexes, i.e., the ratios of the formed phase I metabolites (berberrubine plus demethyleneberberine) to the amount of berberine plus the formed metabolites in the plasma, showed that the in vivo metabolism of berberine was not influenced by PEG400 ( $p>$ 0.05, Fig. 6C).

\section{Effects of PEG400 on the solubility of berberine}

As shown in Fig. 7, berberine was completely dissolved in 50\% PEG400 (10.5 $\left.\mathrm{mg} \mathrm{mL}^{-1}\right)$, while its solubility in water was much lower $\left(p<0.01,1.7 \mathrm{mg} \mathrm{mL}^{-1}\right)$.

\section{Effects of PEG400 on the systemic exposure of berberine and related metabolites}

As shown in Fig. 8A, the systemic exposure level $\left(\mathrm{AUC}_{0-4} \mathrm{~h}\right)$ of berberine in mice was largely increased by $50 \%$ PEG400 ( $p<$ 0.01 , from 30.6 to $188.0 \mathrm{ng} \mathrm{h} \mathrm{mL}{ }^{-1}$ ). As shown in Fig. 8B, the total amount of berberine plus its related metabolites (berberrubine and demethyleneberberine) was also increased. The $\mathrm{AUC}_{0-4} \mathrm{~h}$ increased from 171.0 to $1158.1 \mathrm{ng} \mathrm{h} \mathrm{mL}{ }^{-1}(p<0.01)$.

\section{Effects of cycloheximide pretreatment on the promotive effects of PEG400}

As shown in Fig. 9, cycloheximide pretreatment significantly decreased the effects of PEG400 on the systemic exposure of

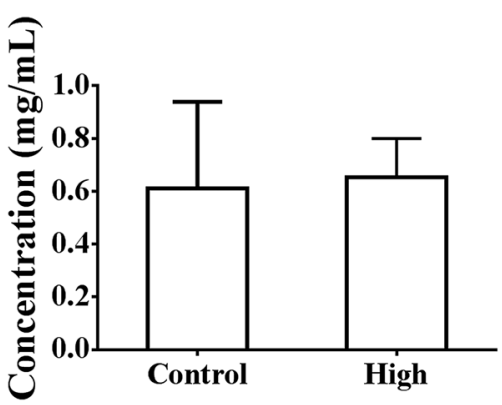

Fig. 4 Total intestinal protein levels at $4 \mathrm{~h}$ after oral administration of PEG400 in mice (mean \pm SD, $n=4$ ). Low and high: $5 \%$ and $50 \%$ PEG400, respectively.

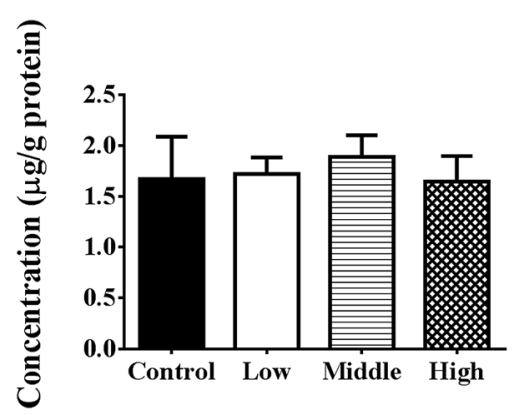

Fig. 5 Effects of various concentrations of PEG400 on the in situ uptake of berberine in the liver (mean $\pm S D, n=4)$. Berberine $(100 \mu \mathrm{M})$ was dissolved in saline or various concentrations of PEG400 $(0.5 \%$, $1.5 \%$, and $5 \% ; 0.04 \mathrm{~mL} \mathrm{~kg}^{-1}$ body weight) and was injected rapidly into the portal vein of mice under light ether anesthesia with diethyl ether. The liver was excised $18 \mathrm{~s}$ later and weighed. The livers were then homogenized, and the concentration of berberine was detected using LC-MS/MS

berberine after oral administration in mice. The $\mathrm{AUC}_{0-3} \mathrm{~h}$ decreased from 388.0 to $106.2 \mathrm{ng} \mathrm{h} \mathrm{mL}{ }^{-1}(p<0.01)$.

\section{Discussion}

Given the extremely low bioavailability of berberine (0.36\%) which is mainly caused by its extensive metabolism, ${ }^{24}$ slight inhibition on metabolizing capacity towards berberine may lead to a significant increase in its systemic exposure. PEG400 was reported to inhibit drug metabolizing enzymes, particularly phase I enzymes. ${ }^{6,7}$ Therefore, it was likely that the effect of PEG400 on the enhanced exposure of berberine would be associated with its effects on drug metabolizing enzymes. However, our results revealed that although PEG400 inhibited the in vitro metabolism of berberine in a concentrationdependent manner, it did not influence the in vivo metabolism of berberine. Although the detail mechanism remains to be elucidated, the inconsistent outcomes between in vitro and in vivo studies might be associated with the intrinsic drawbacks of the in vitro test systems. ${ }^{39}$ For example, liver microsomes, the most widely used in vitro system for drug metabolism and 

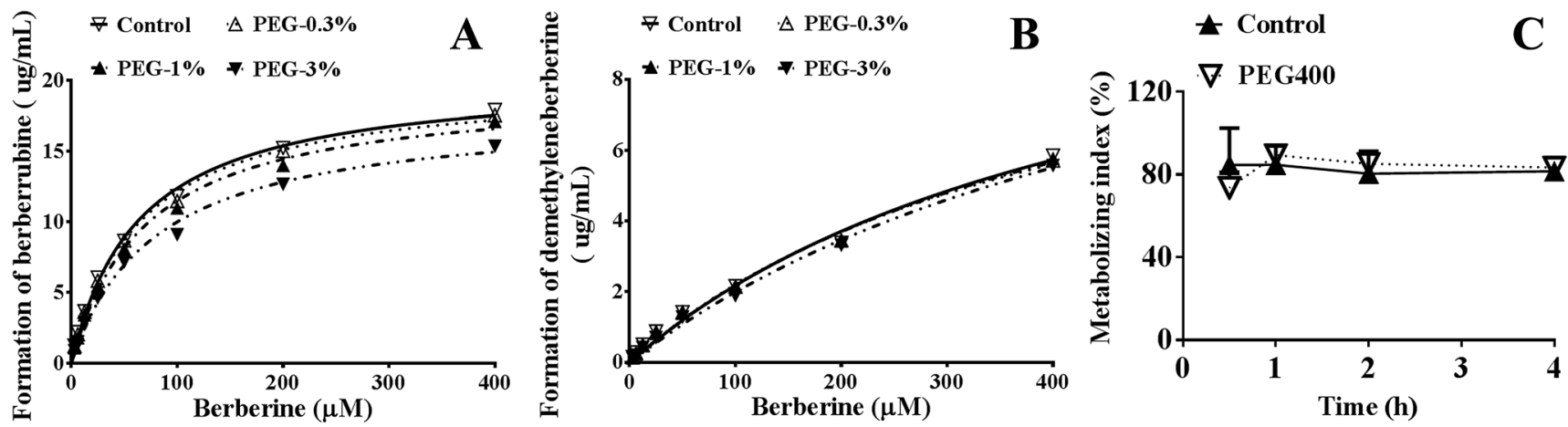

Fig. 6 Effects of PEG400 on the in vitro and in vivo metabolism of berberine (mean \pm SD, $n=3$ for (A) and (B), $n=6$ for (C)). (A and B) Effects of various concentrations of PEG400 $(0.3 \%, 1 \%$, and $3 \%)$ on the in vitro metabolism of berberine in mouse hepatic microsomes. (C) Effects of highconcentration (50\%) PEG400 on the in vivo metabolic indexes of berberine. Data are shown as the ratios of the formatted phase I metabolites (berberrubine plus demethyleneberberine) to the amount of berberine plus the formed metabolites in plasma.

inhibition studies, do not represent the true in vivo situation because they contain only the endoplasmic reticulum-localized enzymes, which means that metabolism via other enzymes will not be detected with this system. ${ }^{40}$

PEG400 has been reported to inhibit the function of P-gp, ${ }^{4}$ which pumps out berberine during its intestinal absorption..$^{25}$ We also found that PEG400 (0.1-5\%) decreased the efflux of berberine from HepG2 and Caco-2 cells in a concentrationdependent manner (data not shown). However, our in vitro absorption results indicated that increased berberine absorption across gut sacs was not due to decreased berberine efflux. Given that PEG400 is a potent inhibitor of both OATP1A2 (ref. 5) and P-gp, ${ }^{4}$ which mediate the uptake ${ }^{41}$ or excretion of berberine ${ }^{26}$ respectively, we hypothesize that these results may be explained by the concerted inhibition of both OATP1A2 and P-gp.

In general, drugs move across epithelial barriers by the transcellular and the paracellular pathway. Hydrophilic drugs usually take the second route, which is regulated by the tight junctions (TJs). Strategies which open TJs by using chemical permeation enhancers in a reversible manner for paracellular drug delivery has got arisen interest. ${ }^{42} \mathrm{FD} 4$ is primarily transported across the intestinal membrane via a paracellular pathway, allowing for easy estimation of intestinal epithelium barrier function..$^{30,38}$ Our results confirmed with the intestinal transport of FD4 suggested that the effects of PEG400 on the enhanced absorption of berberine resulted from the reversible opening of paracellular TJs. These results were consistent with a report by Nakanishi et al. (1983), who found that the decreased rectal permeability induced by $50 \%$ PEG400 returned to the normal state within $2 \mathrm{~h}^{43}$ TJs are composed of proteins including transmembrane proteins (like occludin and claudins) and cytoplasmic plaque proteins (like ZO-1, ZO-2, ZO-3, cingulin, and $7 \mathrm{H6} 6 .{ }^{44}$ Chemical permeation enhancers may act directly and specifically on the extracellular loops of TJ proteins and the TJ-associated membrane microdomains. ${ }^{44}$ However, the mechanism of PEG400 in terms of opening the paracellular TJs remained to be elucidated.

After being absorbed and transiting across the enterocytes, drugs enter into the blood capillaries or lymph capillaries. ${ }^{45}$ The former is the more common pathway because the fluid flow of the portal blood is 500-fold higher than that of the intestinal lymph. ${ }^{45}$ However, the latter pathway is more permeable, and drugs transported via the intestinal lymphatic system can bypass the liver and thus avoid hepatic first-pass metabolism. ${ }^{45}$ Indeed, lymphatic drug transport has been reported to be a contributor to the oral bioavailability of various lipophilic drugs and xenobiotics ${ }^{45}$ Cycloheximide pretreatment is a widely used method to block chylomicron flow and does not affect other absorption pathways. ${ }^{37,46-48}$ Our results confirmed by cycloheximide pretreatment indicated that the lymphatic system played an important role in the enhanced absorption of berberine by PEG400. We assumed that increased absorption of berberine by PEG400 may increase berberine exposure to the lymphatic pathway, thereby contributing to the systemic exposure of orally available berberine. Given that chylomicrons consist of a core of triglyceride (85-92\%) and cholesterol, and a monolayer of phospholipid (6-12\%), cholesterol (1-3\%) and protein $(1-2 \%),{ }^{37}$ lipid solubility therefore has a major role in lymphatic drug transport. For a weak acid or weak base like

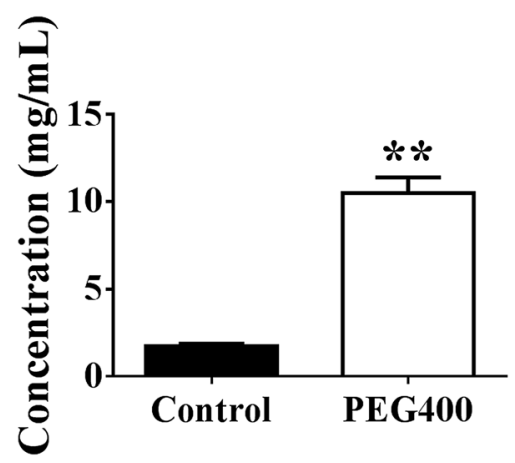

Fig. 7 Solubility of berberine dissolved in water or 50\% PEG400 (mean $\pm \mathrm{SD}, n=3$ ). Ten milligrams of berberine was added to $1 \mathrm{~mL}$ water or $50 \%$ PEG400. The suspensions were then subjected to ultrasound for $1 \mathrm{~h}$ followed by sitting at room temperature (about $22^{\circ} \mathrm{C}$ ) for $5 \mathrm{~h}$. The samples were centrifuged at $24000 \times g$ for $6 \mathrm{~min}$, and the supernatants were collected and measured using LC-MS/MS. ** $p<0.01$ versus the control. 

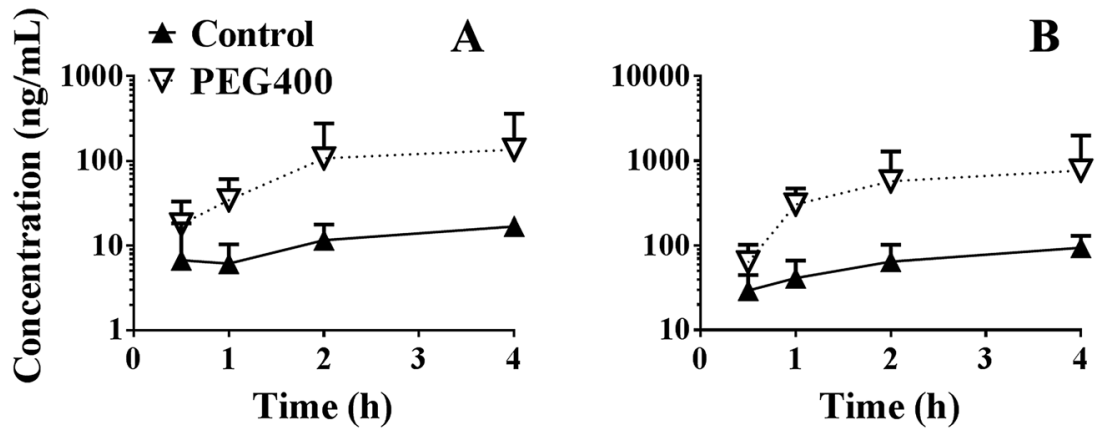

Fig. 8 Effects of PEG400 on the systemic exposure of berberine (A) and total amount of berberine plus its phase I metabolites (B) (mean \pm SD, $n$ =6). Mice were orally administered $200 \mathrm{mg} \mathrm{kg}^{-1}$ berberine dissolved in water or $50 \%$ PEG400. Blood was collected into heparinized tubes at the designated time points $(0.5,1,2$, and $4 \mathrm{~h})$. The plasma was collected and analyzed using LC-MS/MS.

berberine, its lipid solubility may be affected by environmental conditions. For example, changes of $\mathrm{pH}$ values along the gastrointestinal tract may lead to different degree of ionization and lipid solubility of the compound. Its lipid solubility may also be affected by co-existed materials. Reportedly, polyethylene glycol 400 increased the partition coefficient of oxybenzone in a concentration dependent manner. ${ }^{49}$ We assumed that PEG400 improved the lymphatic transport of berberine via increasing its lipid solubility. However, it remained to be verified.

Oral PEG400 is generally considered a highly safe organic cosolvent. ${ }^{50}$ For example, repeated oral administration of PEG400 $(5,50$, or $100 \%)$ at a volume of $5 \mathrm{~mL}$ per $\mathrm{kg}$ per day for 15 days induces mucosal changes in the stomach, but not the intestine of rats..$^{51}$ In the study, no significant changes in the general condition, body weight, food consumption, hematology, or gross findings at necropsy were observed during the treatment period, with the exception of loose stools in rats treated with 50 or $100 \mathrm{v} / \mathrm{v} \%$ PEG400. ${ }^{51}$ We had verified that oral $50 \%$ PEG400 at $20 \mathrm{~mL} \mathrm{~kg}^{-1}$ did not cause acute toxicity in mice (data not shown). In this study, the results of LDH and protein assays suggested that PEG400 did not cause intestinal membrane

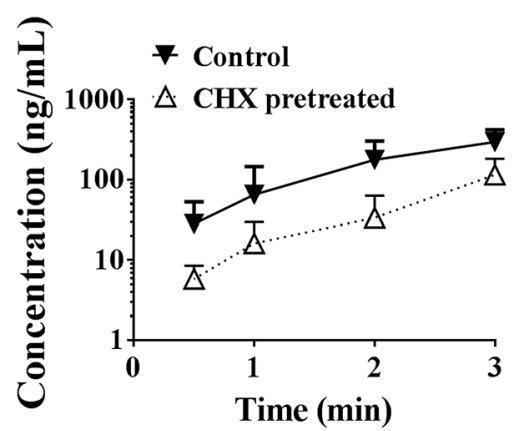

Fig. 9 Effects of chylomicron flow blocking on the effects of PEG400 on systemic exposure of oral berberine in mice (mean $\pm \mathrm{SD}, n=6$ ). Mice received intraperitoneal injection of saline or cycloheximide (10 $\mathrm{mg} \mathrm{kg}^{-1}$ ). Two hours later, the mice were orally administered $200 \mathrm{mg} \mathrm{kg}^{-1}$ berberine dissolved in 50\% PEG400 at the dose volume of $0.2 \mathrm{~mL} / 10 \mathrm{~g}$ body weight. Plasma samples were prepared and analyzed. $\mathrm{CHX}$, cycloheximide. damage. Although these data were not enough to warrant the safety of high concentration of PEG400 especially in clinical applications, they did encourage more studies in this field.

Briefly speaking, our results provided new insights into the pharmaceutical effects of PEG400 from following aspects. First, our results confirmed that PEG400 is not an inert solubilizing agent as was believed, ${ }^{50}$ on the contrary, it showed profound effects on the intestinal absorption and systemic exposure of oral drugs like berberine. Second, previous studies have suggested that PEG400 shows concentration-dependent effects on the absorption of oral drugs, ${ }^{12,52}$ however, our results showed that PEG400 had biphasic effects on the absorption of oral berberine. That's to say, lower concentration of PEG400 decreased but higher concentration increased the absorption of berberine. Third, given that berberine is an alkaloid, the result was also contradictory to the study which showed that PEG400 decreases the absorption of weak bases. ${ }^{13}$ Fourth, our results discovered new mechanisms for the enhancing effects of PEG400 on oral drugs: promoting the paracellular absorption as well as lymphatic transportation of berberine.

\section{Conclusion}

In conclusion, our data showed that PEG400 could act as more than a co-solvent. Briefly, high concentration of PEG400 increased the systemic exposure of berberine by increasing its solubility, prompting its intestinal paracellular absorption and lymphatic transport. Given that PEG400 was widely considered to be inert, our results provide new insights into the effects and mechanisms of PEG400 on the systemic exposure of oral drugs. Especially, the results indicated that high concentration of PEG400 could act like chemical permeation enhancers, which reversibly promote the paracellular drug delivery. Although its potency and mechanism should be further explored and its safety should be carefully evaluated, our results did encourage further studies on the application of PEG400 in drug delivery.

\section{Conflicts of interest}

The authors state no conflict of interest. 


\section{Acknowledgements}

This work was financially supported by the National Natural Science Foundation of China (No. 81202986 and No. 81273658).

\section{References}

1 G. L. Amidon, H. Lennernas, V. P. Shah and J. R. Crison, Pharm. Res., 1995, 12, 413-420.

2 H. D. Williams, N. L. Trevaskis, S. A. Charman, R. M. Shanker, W. N. Charman, C. W. Pouton and C. J. Porter, Pharmacol. Rev., 2013, 65, 315-499.

3 D. A. Ashiru, R. Patel and A. W. Basit, Pharm. Res., 2008, 25, 2327-2333.

4 B. M. Johnson, W. N. Charman and C. J. Porter, AAPS PharmSciTech, 2002, 4, E40.

5 A. Engel, S. Oswald, W. Siegmund and M. Keiser, Mol. Pharm., 2012, 9, 2577-2581.

6 D. R. Mudra and R. T. Borchardt, J. Pharm. Sci., 2010, 99, 1016-1027.

7 M. M. Cotreau-Bibbo, L. L. von Moltke and D. J. Greenblatt, J. Pharm. Sci., 1996, 85, 1180-1185.

8 A. W. Basit, J. M. Newton, M. D. Short, W. A. Waddington, P. J. Ell and L. F. Lacey, Pharm. Res., 2001, 18, 1146-1150.

9 J. D. Schulze, W. A. Waddington, P. J. Eli, G. E. Parsons, M. D. Coffin and A. W. Basit, Pharm. Res., 2003, 20, 1984-1988. 10 L. E. Riad and R. J. Sawchuk, Pharm. Res., 1991, 8, 491-497.

11 A. Beig, J. M. Miller and A. Dahan, Eur. J. Pharm. Biopharm., 2012, 81, 386-391.

12 G. E. Flaten, K. Luthman, T. Vasskog and M. Brandl, Eur. J. Pharm. Sci., 2008, 34, 173-180.

13 S. Bendels, O. Tsinman, B. Wagner, D. Lipp, I. Parrilla, M. Kansy and A. Avdeef, Pharm. Res., 2006, 23, 2525-2535.

14 G. Fan, M. Y. Zhang, X. D. Zhou, X. R. Lai, Q. H. Yue, C. Tang, W. Z. Luo and Y. Zhang, Anal. Chim. Acta, 2012, 747, 76-83.

15 P. R. Vuddanda, S. Chakraborty and S. Singh, Expert Opin. Invest. Drugs, 2010, 19, 1297-1307.

16 H. L. Zhao, Y. Sui, C. F. Qiao, K. Y. Yip, R. K. Leung, S. K. Tsui, H. M. Lee, H. K. Wong, X. Zhu, J. J. Siu, L. He, J. Guan, L. Z. Liu, H. X. Xu, P. C. Tong and J. C. Chan, Diabetes, 2012, 61, 933-943.

17 Y. Deng, J. Xu, X. Zhang, J. Yang, D. Zhang, J. Huang, P. Lv, W. Shen and Y. Yang, Autophagy, 2014, 10, 1776-1786.

18 Q. Liu, X. Xu, M. Zhao, Z. Wei, X. Li, X. Zhang, Z. Liu, Y. Gong and C. Shao, Mol. Cancer Ther., 2015, 14, 355-363.

19 C. Spatuzza, L. Postiglione, B. Covelli, M. Ricciardone, C. Benvenuti, P. Mondola and A. Belfiore, Front. Pharmacol., 2014, 5, 230.

20 S. Menees, R. Saad and W. D. Chey, Nat. Rev. Gastroenterol. Hepatol., 2012, 9, 661-674.

21 S. Song, M. Qiu, Y. Chu, D. Chen, X. Wang, A. Su and Z. Wu, Antimicrob. Agents Chemother., 2014, 58, 5068-5078.

22 G. Derosa and P. Maffioli, Curr. Top. Med. Chem., 2014, 14, 200-206.

23 S. Spinozzi, C. Colliva, C. Camborata, M. Roberti, C. Ianni, F. Neri, C. Calvarese, A. Lisotti, G. Mazzella and A. Roda, J. Nat. Prod., 2014, 77, 766-772.
24 Y. T. Liu, H. P. Hao, H. G. Xie, L. Lai, Q. Wang, C. X. Liu and G. J. Wang, Drug Metab. Dispos., 2010, 38, 1779-1784.

25 X. Zhang, F. Qiu, J. Jiang, C. Gao and Y. Tan, Xenobiotica, 2011, 41, 290-296.

26 P. L. Tsai and T. H. Tsai, Drug Metab. Dispos., 2004, 32, 405-412.

27 C. S. Liu, Y. R. Zheng, Y. F. Zhang and X. Y. Long, Fitoterapia, 2016, 109, 274-282.

28 S. Y. Gui, L. Wu, D. Y. Peng, Q. Y. Liu, B. P. Yin and J. Z. Shen, Pharmazie, 2008, 63, 516-519.

29 S. Pund, G. Borade and G. Rasve, Phytomedicine, 2014, 21, 307-314.

30 B. L. Ma, M. K. Yao, J. Zhong, Y. M. Ma, C. L. Gao, J. S. Wu, F. R. Qiu, C. H. Wang and X. H. Wang, Drug Metab. Dispos., 2012, 40, 381-388.

31 R. Weaver and R. J. Riley, Rapid Commun. Mass Spectrom., 2006, 20, 2559-2564.

32 V. Anuta, G. M. Nitulescu, C. E. Dinu-Pirvu and O. T. Olaru, Molecules, 2014, 19, 16381-16401.

33 V. Vijaya Bhaskar, A. Middha, S. Tiwari and S. Shivakumar, J. Chromatogr. B: Anal. Technol. Biomed. Life Sci., 2013, 926, 6876.

34 A. Zhang, C. Wang, Q. Liu, Q. Meng, J. Peng, H. Sun, X. Ma, X. Huo and K. Liu, Drug Metab. Dispos., 2013, 41, 994-1003. 35 W. Xie, D. Gu, J. Li, K. Cui and Y. Zhang, PLoS One, 2011, 6, e24520.

36 T. Lao-ong, W. Chatuphonprasert, N. Nemoto and K. Jarukamjorn, Pharm. Biol., 2012, 50, 1007-1012.

37 A. Dahan and A. Hoffman, Eur. J. Pharm. Sci., 2005, 24, 381388.

38 K. A. Hamid, H. Katsumi, T. Sakane and A. Yamamoto, Int. J. Pharm., 2009, 379, 100-108.

39 E. F. Brandon, C. D. Raap, I. Meijerman, J. H. Beijnen and J. H. Schellens, Toxicol. Appl. Pharmacol., 2003, 189, 233-246. 40 N. Plant, Drug Discovery Today, 2004, 9, 328-336.

41 C. Chen, Z. T. Wu, L. L. Ma, X. Ni, Y. F. Lin, L. Wang, K. P. Chen, C. G. Huang and G. Pan, Xenobiotica, 2015, 45, 1138-1146.

42 L. Gonzalez-Mariscal, Y. Posadas-Torrentera, J. Miranda, P. Uc, J. M. Ortega-Olvera and S. Hernandez, Curr. Pharm. Des., 2016, 22, 5313-5346.

43 K. Nakanishi, M. Masada and T. Nadai, Chem. Pharm. Bull., 1983, 31, 4161-4166.

44 M. A. Deli, Biochim. Biophys. Acta, 2009, 1788, 892-910.

45 J. A. Yanez, S. W. Wang, I. W. Knemeyer, M. A. Wirth and K. B. Alton, Adv. Drug Delivery Rev., 2011, 63, 923-942.

46 S. Attili-Qadri, N. Karra, A. Nemirovski, O. Schwob, Y. Talmon, T. Nassar and S. Benita, Proc. Natl. Acad. Sci. U. S. A., 2013, 110, 17498-17503.

47 Z. Zhang, F. Gao, H. Bu, J. Xiao and Y. Li, Nanomedicine, 2012, 8, 740-747.

48 F. Gao, Z. Zhang, H. Bu, Y. Huang, Z. Gao, J. Shen, C. Zhao and Y. Li, J. Controlled Release, 2011, 149, 168-174.

49 C. J. Mbah, Pharmazie, 2007, 62, 38-40.

50 R. G. Strickley, Pharm. Res., 2004, 21, 201-230.

51 Y. Ueda, M. Tsuboi, Y. Ota, M. Makita, T. Aoshima, M. Nakajima and I. Narama, J. Toxicol. Sci., 2011, 36, 811-815. 52 A. Dahan and J. M. Miller, AAPS J., 2012, 14, 244-251. 